\title{
Pyruvate promotes tumor angiogenesis through HIF-1-dependent PAI-1 expression
}

\author{
SEUNG-YOUN JUNG* ${ }^{*}$, HYUN SEOK SONG* ${ }^{*}$, SHI-YOUNG PARK, SOO-HAK CHUNG and YUNG-JIN KIM \\ Department of Molecular Biology, College of Natural Science, Pusan National University, \\ Busan 609-735, Republic of Korea
}

Received August 22, 2010; Accepted October 25, 2010

DOI: $10.3892 /$ ijo.2010.859

\begin{abstract}
Cancer cells usually obtain energy from a high rate of glycolysis rather than oxidative phosphorylation under normoxia as well as hypoxia. Under these circumstances, pyruvate, the end-product of glycolysis, accumulates in cancer cells. We have previously reported that pyruvate activates endothelial cells and induces angiogenesis. Here, we examined the angiogenic activity of pyruvate in tumor cells. Plasminogen activator inhibitor-1 (PAI-1), the gene most upregulated by pyruvate, showed a pro-angiogenic activity, which was abolished by a PAI-1 neutralizing antibody. Moreover, stabilization of hypoxia-inducible factor- $1 \alpha$ (HIF-1 $\alpha)$ by pyruvate was required for induction of PAI-1 transcription through direct binding to hypoxia response element-2 (HRE-2) on the promoter. These results suggest that pyruvate can activate the angiogenic activity of cancer cells under normoxia and that PAI-1 may act as a pro-angiogenic factor in pyruvate-induced angiogenesis.
\end{abstract}

\section{Introduction}

Metabolic features of cancer cells deviate significantly from those of normal cells. For example, overexpression of glucose transporters and various glycolytic enzymes, high rates of glycolysis, excessive release of lactate and protons, reduction of the oxidative phosphorylation (OXPHOS) pathway, increased lipid synthesis, and inhibition of the B-oxidation pathway are observed in cancer cells (1-3). In particular, it is known that the energy of cancer cells is usually supplied from a high rate of glycolysis rather than the OXPHOS pathway under normoxic conditions, called the Warburg effect $(4,5)$. Due to aerobic glycolysis in cancer cells, pyruvate

Correspondence to: Dr Yung-Jin Kim, Department of Molecular Biology, Pusan National University, Busan 609-735, Republic of Korea

E-mail: yjinkim@pusan.ac.kr

*Contributed equally

Key words: pyruvate, angiogenesis, plasminogen activator inhibitor-1, hypoxia-inducible factor- $1 \alpha$ and lactate, the end-products of glycolysis, are accumulated $(2,6)$. Recently, accumulated pyruvate in the cell may induce hypoxia-inducible factor- $1 \alpha$ (HIF- $1 \alpha$ ) under normoxic conditions, which results in acceleration of the glycolytic phenotype of cancer cells (4).

Angiogenesis, the process of new blood vessel formation from pre-existing vessels, is essential for physiological and pathological conditions, including aggressive tumor development $(7,8)$. It is tightly controlled by various activators and inhibitors (8-10). However, tumor cells induce angiogenesis in order to supply oxygen and nutrients by secretion of angiogenic activators (11). We have previously reported that pyruvate is able to induce both in vivo and in vitro angiogenesis of endothelial cells (12). Pyruvate upregulates vascular endothelial cell growth factor (VEGF) and fibroblast growth factor receptor-2 (FGFR-2) and leads to activation of proliferation, migration, and tube-like differentiation of endothelial cells. It is suggested that secreted pyruvate from cancer cells may directly activate endothelial cells to form new blood vessels.

Therefore, we examined the possibility that accumulated pyruvate induces angiogenic properties in cancer cells, and also investigated the mechanism which is responsible for induction of angiogenesis. Here, we show that pyruvate induces angiogenesis in HepG2 cells and that upregulation of plasminogen activator inhibitor-1 (PAI-1) by HIF-1 plays a major role in pyruvate-induced angiogenesis.

\section{Materials and methods}

Materials. Minimal essential medium (MEM), fetal bovine serum (FBS), penicillin and streptomycin were purchased from Gibco BRL (Rockville, MD). Pyruvate was purchased from Sigma (St. Louis, MO; cat. no.: P1656). Lipofectamine, PLUS reagent, and TRIzol were purchased from Invitrogen (Carlsbad, CA). T4-polynucleotide kinase, alkaline phosphatase and other restriction enzymes were purchased from New England Biolabs (Beverly, MA). The luciferase assay system, T4 ligase, M-MLV reverse transcriptase and the Wizard Genomic DNA purification kit were purchased from Promega (Madison, WI). For Western blotting, HIF- $1 \alpha$ antibody was purchased from BD Science (Palo Alto, CA). For the electrophoretic mobility shift assay (EMSA), HIF-1 $\alpha$ antibody was purchased from Santa Cruz (Santa Cruz, CA). For HIF-1 $\alpha$ inhibition, YC-1 was purchased from A.G. 
Scientific (San Diego, CA). PAI-1 neutralizing antibody was purchased from R\&D Systems (Minneapolis, MN). For the in vitro angiogenesis assay, Matrigel was purchased from BD Science.

Cell culture. HepG 2 cells $\left(2.2 \times 10^{6}\right.$ cells/100-mm dish; 40,000 cells $/ \mathrm{cm}^{2}$ ) were cultured in MEM, supplemented with heat-inactivated $10 \%$ fetal bovine serum, $100 \mathrm{U} / \mathrm{ml}$ of penicillin, and $100 \mu \mathrm{g} / \mathrm{ml}$ of streptomycin in a $37^{\circ} \mathrm{C}$ incubator with a humidified atmosphere containing $5 \% \mathrm{CO}_{2}$. Before exposure to hypoxia and chemical reagents, seeded cells were stabilized for $24 \mathrm{~h}$ in an incubator. For hypoxic treatment, cells were transferred to an anaerobic chamber (Forma Scientific; Marietta, $\mathrm{OH}$ ) with a humidified atmosphere of $2 \% \mathrm{O}_{2}$ and $\mathrm{CO}_{2}$ balanced with $\mathrm{N}_{2}$ and incubated at $37^{\circ} \mathrm{C}$ for 12 h. HUVECs (Cambrex; Walkersville, MD) were grown according to the manufacturer's protocol in EBM-2 medium (Cambrex) supplemented with the EGM-2 kit containing 2\% fetal calf serum (FCS), $0.04 \%$ hydrocortisone, $0.4 \%$ hFGF-B, $0.1 \% \mathrm{VEGF}$, and $0.1 \%$ heparin. HUVECs in passages 5 through 8 were used in the tube formation assay.

Tube formation assay in vitro. HepG 2 cells $\left(2.2 \times 10^{6}\right.$ cells/ 100-mm dish; 40,000 cells $/ \mathrm{cm}^{2}$ ) were cultured with or without $3 \mathrm{mM}$ pyruvate for $12 \mathrm{~h}$, and culture media were then collected. HUVECs $\left(5 \times 10^{4}\right.$ cells/well $)$ were seeded on a layer of polymerized Matrigel with collected media in 24-well plates (NUNC; Roskilde, Denmark). PAI-1 neutralizing antibody $(2 \mu \mathrm{g} / \mathrm{ml})$ was used for inhibition of PAI- 1 in pyruvate-treated media. After $12 \mathrm{~h}$, changes in cell morphology were observed under a phase-contrast microscope and photographed at x100 magnification.

Total RNA preparation and reverse transcriptase-polymerase chain reaction. Total RNA for use in RT-PCR was isolated using TRIzol reagent according to the manufacturer's instructions. cDNA was made with oligo-dTTP using M-MLV reverse transcriptase. PCR amplification was performed under optimized conditions for each primer pair. The following oligonucleotide primer pairs were used: PAI-1, 5'-GTC AAG CAA GTG GAC TTT TC-3' (forward) and 5'-GGT CTG AAA GAC TCG TGA AG-3' (reverse); ß-actin, 5'-GTG GGG CGC CCC AGG CAC CAG GGC-3' (forward) and 5'-CTC CTT AAT GTC ACG CAC GAT TTC-3' (reverse); HIF-1 $\alpha, 5$-CCC ATT CCT CAC CCA TCA AA-3' (forward) and 5'-GGG GCC AGC AAA GTT AAA GC-3' (reverse); GAPDH, 5'-ACG GAT TTG GTC GTA TTG GG-3' (forward) and 5'-TGA TTT TGG AGG GAT CTC GC-3' (reverse). PCR products were electrophoresed on $1 \%$ agarose gels and visualized by ethidium bromide staining under UV trans-illumination.

Western blot analysis. Total protein $(50 \mu \mathrm{g})$ was loaded onto an $8 \%$ sodium dodecyl sulfate-polyacrylamide gel, and, after electrophoresis, blotted onto Hybond-P PVDF membranes (Amersham; Piscataway, NJ). Membrane with protein was blocked for $2 \mathrm{~h}$ at room temperature in a blocking solution (5\% skim milk in TBS containing $0.1 \%$ Tween-20), and then incubated with primary antibodies against HIF-1 $\alpha$ (1:500), PAI-1 $(1: 1000)$, and $\alpha$-tubulin $(1: 2500)$. Peroxidase- conjugated anti-mouse secondary antibody was used at a dilution of 1:2500. Signals were visualized using PicoEPD Western reagent (ElpisBiotech; Daejeon, Korea). Each assay was performed in triplicate.

Plasmid constructs. For preparation of genomic DNA, the Wizard Genomic DNA purification kit was used according to the manufacturer's instructions. The human PAI-1 promoter region (Ensembl ID: ENSG00000106366), extending from transcription initiation positions -799 to +21 was amplified from a purified human genomic DNA of HepG2 cells with the aid of an upstream and downstream primer incorporating restriction sites for KpnI (13-16). The sequence of the upstream primer was 5'-GGC GGT ACC ATG GTA ACC CCT GGT CCC G-3' and that of the downstream primer was 5'-GGC GGT ACC TGC AGC CAA ACA CAG CTG TG-3' (underline indicates the $K p n I$ restriction enzyme recognition site). Following enzyme restriction, the PCR product was ligated into the luciferase reporter plasmid, pGL3-basic (Promega), yielding a pGL3-hPAI-1-wt construct containing the 5 putative hypoxia response element motifs (16). HRE-2, the functional HRE motif $(14,16)$, was mutagenized using a QuickChange Site-Directed mutagenesis kit (Stratagene; La Jolla, CA). For mutation, primer 5'-CTG AAT GCT CTT ACA CGA TAT CAC ACA CAG AGC AGC AC-3' (underline; changed nucleotides) was used. The generated plasmid was designated as pGL3-hPAI-1-mut.

Cell transfection and reporter assay. HepG2 cells $\left(1.4 \times 10^{5}\right.$ cells/well; 40,000 cells $/ \mathrm{cm}^{2}$ ) were seeded and transiently transfected in 12-well plates using Lipofectamine and PLUS reagent according to the manufacturer's instructions (NUNC). In brief, $140 \mathrm{ng}$ of the appropriate PAI-1 wild-type HRE-2 promoter or PAI-1 mutant HRE-2 promoter Firefly Luciferase construct was transfected. pCMV-lacZ was cotransfected with each construct as a control for transfection efficiency. Total amount of DNAs were maintained by addition of $490 \mathrm{ng}$ of pcDNA3.1/His C. Twelve hours after transfection, cells were treated with hypoxia and pyruvate for $12 \mathrm{~h}$. At the end of treatment, the cells were harvested in Passive Lysis Buffer (Luciferase Assay System, Promega). Luciferase activity was determined using a microplate reader (Wallac Victor, PerkinElmer; Boston, MA), following the manufacturer's protocol. Relative luciferase activity was normalized against the activity of B-gal. Each value represents the mean of at least four wells, and similar results were obtained in two different experiments. Statistical comparisons between groups were performed using the Student's t-test. Data were considered statistically significant at $\mathrm{P}<0.05$.

Preparation of nuclear extracts. Cells were washed twice with ice-cold phosphate-buffered saline (PBS) and harvested. Cells were resuspended in $100 \mu 1$ lysis buffer [10 mM Tris$\mathrm{HCl}$ (pH 7.9), $1.5 \mathrm{mM} \mathrm{MgCl}, 10 \mathrm{mM} \mathrm{KCl}, 0.5 \mathrm{mM}$ DTT, $0.1 \% \mathrm{NP} 40$, and $0.5 \mathrm{mM}$ PMSF], and then incubated at $4^{\circ} \mathrm{C}$ for $15 \mathrm{~min}$. The mixtures were centrifuged at $13,000 \mathrm{x} \mathrm{g}$ for $10 \mathrm{~min}$ at $4^{\circ} \mathrm{C}$. The nuclei pellet was resuspended in $30 \mu 1$ extraction buffer $\left[20 \mathrm{mM}\right.$ Tris- $\mathrm{HCl}(\mathrm{pH} 7.9), 1.5 \mathrm{mM} \mathrm{MgCl}_{2}$, $0.5 \mathrm{mM}$ DTT, $25 \%$ glycerol, $420 \mathrm{mM} \mathrm{NaCl}, 0.2 \mathrm{mM}$ EDTA, and $0.5 \mathrm{mM}$ PMSF] and vortexed briefly. After standing 
at $4^{\circ} \mathrm{C}$ for $15 \mathrm{~min}$, the mixture was centrifuged at $4^{\circ} \mathrm{C}$ for $10 \mathrm{~min}$ and the supernatant was transferred to a fresh tube. Extracts were diluted with $60 \mu 1$ dilution buffer $[20 \mathrm{mM}$ Tris- $\mathrm{HCl}$ (pH 7.9), $50 \mathrm{mM} \mathrm{KCl,} 0.5 \mathrm{mM}$ DTT, 20\% glycerol, $0.2 \mathrm{mM}$ EDTA, and $0.5 \mathrm{mM}$ PMSF]. Protein concentration was determined using a BCA protein assay kit (Sigma).

Electrophoretic mobility shift assay. Sequences of the sense strand of the oligonucleotide probe used for EMSA were as follows: 5'-CCT GAA TGC TCT TAC ACA CGT ACA CAC ACA GAG CAG C-3' (human PAI-1 HRE-2). Sense and antisense strands were annealed and end-labeled with $\left[\gamma^{32} \mathrm{P}\right]$-ATP (Amersham) using T4-polynucleotide kinase. Unincorporated nucleotide was removed by gel filtration using ProbeQuant ${ }^{\mathrm{TM}}$ G-50 micro Columns (Amersham). For the DNA-protein interaction, $2-5 \times 10^{4} \mathrm{cpm}$ of oligonucleotide probe was incubated with $30 \mu \mathrm{g}$ of nuclear extract and $0.5 \mu \mathrm{g}$ of sonicated, denatured salmon sperm DNA in $10 \mathrm{mM}$ Tris$\mathrm{HCl}$ (pH 7.8), $50 \mathrm{mM} \mathrm{KCl}, 50 \mathrm{mM} \mathrm{NaCl}, 1 \mathrm{mM} \mathrm{MgCl}_{2}$, $1 \mathrm{mM}$ EDTA, $5 \mathrm{mM}$ dithiothreitol, and $5 \%$ glycerol for $30 \mathrm{~min}$ on ice in a total volume of $20 \mu \mathrm{l}$. The reaction mixture was subjected to electrophoresis $(200 \mathrm{~V}$ in $0.25 \mathrm{X}$ Tris-buffered EDTA) using 4\% non-denaturing polyacrylamide gels. Dried gels were subjected to autoradiography for $16 \mathrm{~h}$. For the competition experiment, a 100-fold molar excess of unlabeled oligonucleotide was added to the binding reaction just prior to addition of radiolabeled probe. For gel supershift analysis, $1 \mu 1$ of rabbit polyclonal antibody against HIF- $1 \alpha$ was added prior the initial $30 \mathrm{~min}$ period of incubation for $2 \mathrm{~h}$ on ice.

\section{Results}

Pyruvate induces angiogenesis through PAI-1 upregulation. To examine the angiogenic effect of pyruvate on tumor cells, HepG 2 cells were incubated with $3 \mathrm{mM}$ of pyruvate for $12 \mathrm{~h}$, and conditioned media (CM) were applied to HUVECs for an in vitro tube formation assay. Formation of tube-like structures was increased by pyruvate-treated CM (Fig. 1A). This result shows that pyruvate may induce angiogenic factors in tumor cells. Thus, we performed cDNA microarray analysis with cDNAs from HepG2 cells treated with $3 \mathrm{mM}$ of pyruvate for $12 \mathrm{~h}$ in order to investigate the angiogenic mechanism of pyruvate. The most highly expressed gene in $3 \mathrm{mM}$ pyruvatetreated HepG2 cells was PAI-1 (8.47-fold) (data not shown). To confirm expression of PAI-1 from cDNA microarray data, we performed RT-PCR analysis using a PAI-1-specific primer set. PAI-1 expression was upregulated by pyruvate, in agreement with the cDNA microarray result (Fig. 1B). PAI-1 is a major inhibitor of both tissue-type and urokinase-type plasminogen activators (tPA and uPA) $(17,18)$. PAI-1 also participates in angiogenesis; however, due to the results of pro-angiogenic and anti-angiogenic actions, the exact role of PAI-1 in this process remains controversial (19-26). Therefore, we used an in vitro tube formation assay in order to verify the role of PAI-1 induced by pyruvate on angiogenesis. Pyruvate-treated CM was applied to HUVECs in a tube formation assay with $2 \mu \mathrm{g} / \mathrm{ml}$ of neutralizing antibody against PAI-1. Whereas pyruvate-treated CM led to differentiation of HUVECs, neutralizing antibody against PAI-1 inhibited tube formation induced by pyruvate-treated CM (Fig. 1C). These
A Control
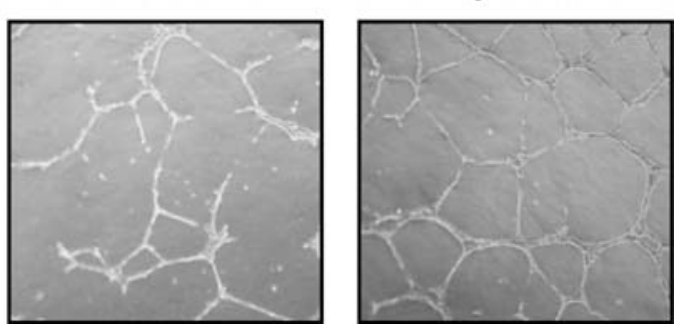

B Control Pyruvate

PAI-1

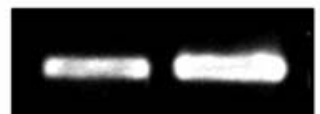

(574 bp)

$\beta$-actin

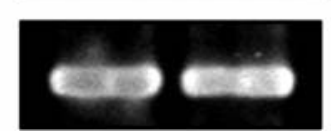

(541 bp)
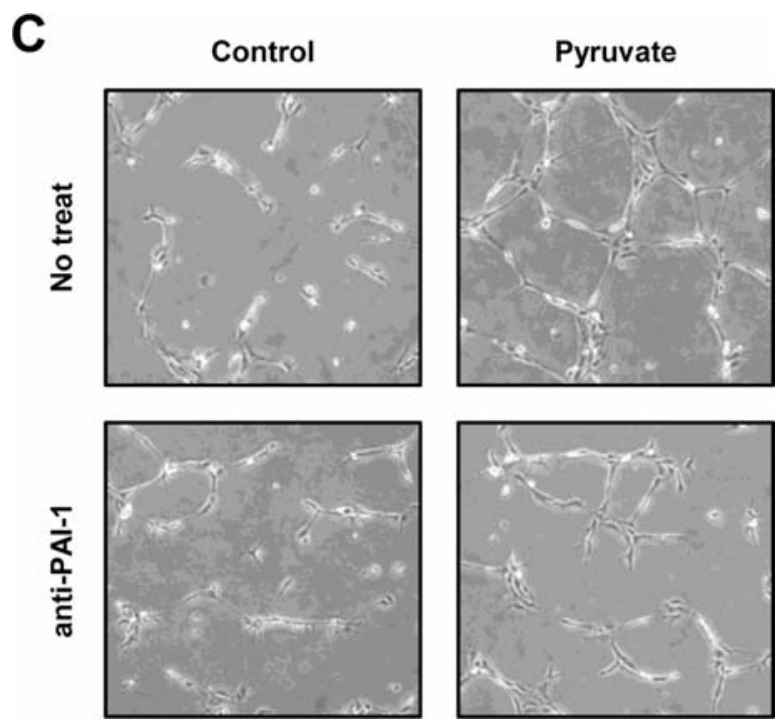

Figure 1. Pyruvate-induced PAI-1 is a pro-angiogenic factor in HUVECs. (A) HUVECs $\left(5 \times 10^{5}\right.$ cells $)$ were seeded on a layer of polymerized Matrigel. Cells were treated with culture media of $3 \mathrm{mM}$ pyruvate-treated HepG2 cells and incubated at $37^{\circ} \mathrm{C}$ for $12 \mathrm{~h}$. Changes in cell morphology were examined under a phase-contrast microscope and photographed (x100). (B) mRNA levels of PAI-1 by pyruvate were confirmed by RT-PCR using the specific primers. HepG2 cells were treated with $3 \mathrm{mM}$ pyruvate for $12 \mathrm{~h}$. (C) HUVECs $\left(5 \times 10^{5}\right.$ cells $)$ were seeded on a layer of polymerized Matrigel. Cells were treated with culture media of $3 \mathrm{mM}$ pyruvate-treated HepG2 cells and incubated at $37^{\circ} \mathrm{C}$ for $12 \mathrm{~h}$. Neutralizing antibody $(2 \mu \mathrm{g} / \mathrm{ml})$ was used as a PAI-1 inhibitor. Changes in cell morphology were examined under a phase-contrast microscope and photographed (x100).

results show that upregulation of PAI-1 by pyruvate induces angiogenesis.

Pyruvate induces PAI-1 transcription through HIF-1a stabilization. As mentioned above, pyruvate in cancer cells stabilized HIF-1 $\alpha$ under normoxic conditions (4). Also, HIF-1 $\alpha$ promotes transcription of the PAI-1 gene under hypoxia $(16,27)$. RT-PCR and Western blot assay were performed for determination of whether pyruvate-induced PAI-1 expression is mediated by HIF- $1 \alpha$ stabilization under normoxic conditions. HIF- $1 \alpha$ and PAI-1 were induced by $3 \mathrm{mM}$ of pyruvate as 
A

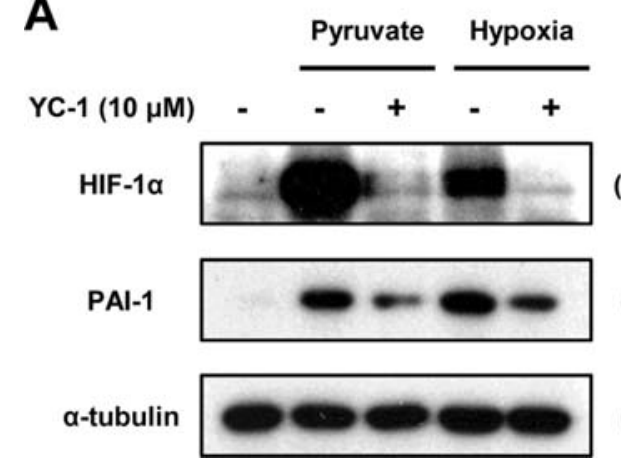

(120 kDa)

$(50 \mathrm{kDa})$

$(50 \mathrm{kDa})$

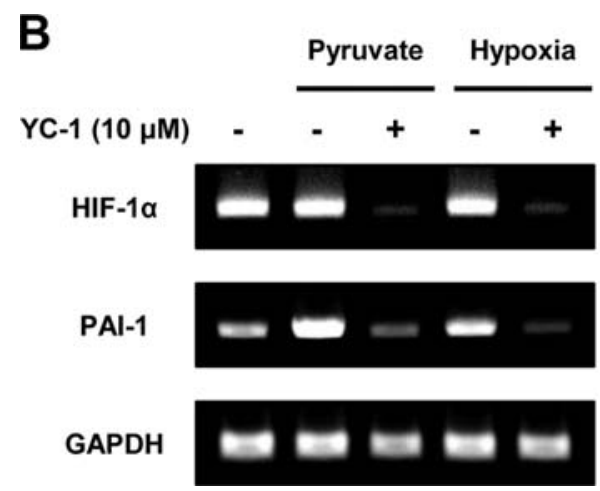

$(530 \mathrm{bp})$

(574 bp)

(231 bp)

Figure 2. Hypoxia and pyruvate-induced PAI-1 expression is mediated by HIF-1 $\alpha$ (A). HepG2 cells were treated with hypoxia or pyruvate and with or without YC-1 for $12 \mathrm{~h}$. Protein levels of HIF-1 $\alpha$ were examined by Western blot analysis. (B) HepG2 cells were treated with hypoxia or pyruvate and with or without YC-1 for $12 \mathrm{~h}$. mRNA levels of HIF-1 $\alpha$ and PAI-1 were examined by RT-PCR using the specific primers.

well as hypoxic conditions (Fig. 2A). Although the mRNA level of HIF-1 $\alpha$ did not change, the mRNA level of the PAI-1 gene increased upon treatment with $3 \mathrm{mM}$ pyruvate (Fig. 2B). To investigate whether HIF- $1 \alpha$ induced by pyruvate can activate PAI-1 transcription, RT-PCR and Western blot were performed with YC-1, a pharmacological inhibitor of HIF-1 $\alpha$ (28-30). The results show that YC-1 suppressed induction of both mRNA and protein levels of HIF- $1 \alpha$ and PAI-1 expression by pyruvate and hypoxia (Fig. 2A and B). These data indicate that pyruvate activates PAI-1 transcription under normoxia via stabilization of HIF- $1 \alpha$.

Pyruvate activates PAI-1 transcription via hypoxia response element-2 (HRE-2) in the PAI-1 promoter. Recently, sequence analysis of the human PAI-1 promoter revealed five putative HRE motifs that show homology with consensus sequence binding with HIF-1, BACGTSSK $(\mathrm{B}=\mathrm{G} / \mathrm{C} / \mathrm{T}, \mathrm{S}=\mathrm{G} / \mathrm{C}$, and $\mathrm{K}=\mathrm{G} / \mathrm{T}$ ) (16). However, only the HRE-2 motif (positions -194 to -187) of the five HREs was actually required for hypoxia-dependent activation (16). To verify that HRE-2 of the PAI-1 promoter is required for activation of PAI- 1 transcription by pyruvate, we performed a promoter activity assay using luciferase reporter vectors with the wild-type promoter $(-799$ to +21$)$ and the HRE-2-mutated promoter (CACGTACA to CGATATCA) (Fig. 3A). Compared to the control, the promoter activity of PAI-1 was increased by $\sim 3$-fold by treatment with pyruvate or hypoxia (Fig. 3B). On the other hand, the promoter containing mutated-HRE did not
A
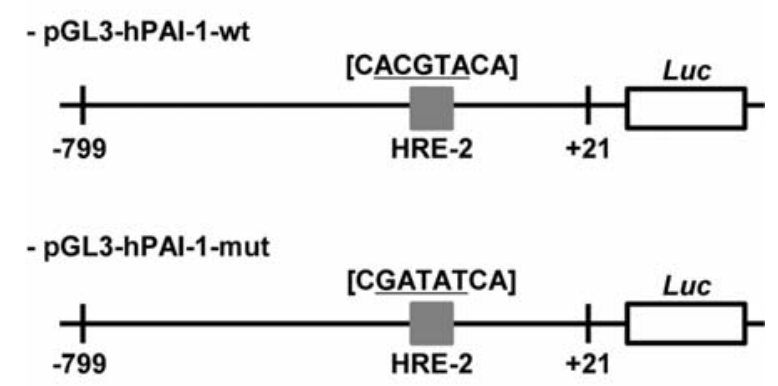

- HRE-2 : -194 to -187

B

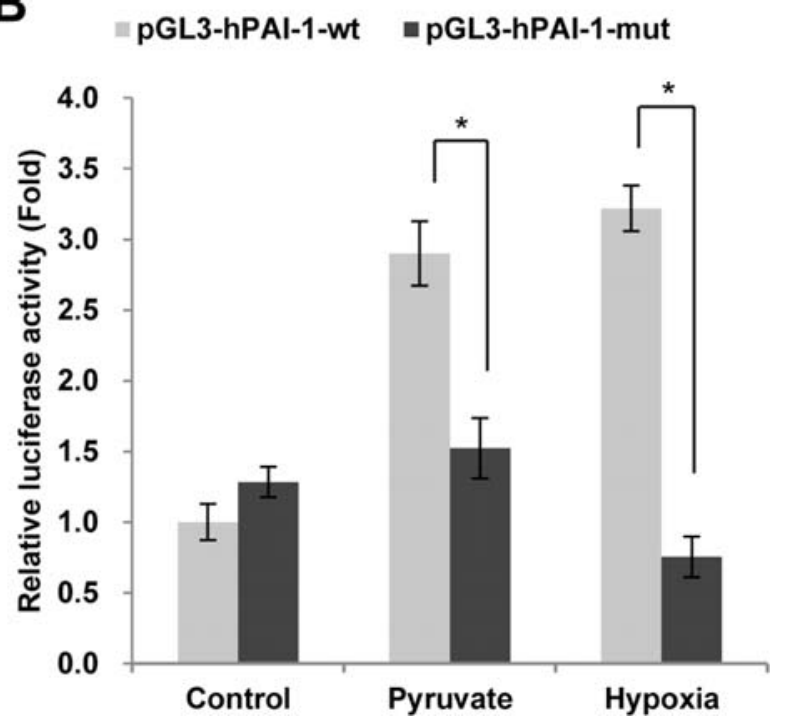

Figure 3. Pyruvate increases PAI-1 promoter activity via HRE-2. (A) Structures of wild-type and mutant PAI-1 promoter constructs. (B) Transcriptional activation of human PAI-1 promoter by pyruvate. Transcriptional activation was measured by a luciferase reporter assay. HepG2 cells were transiently transfected with wild-type or mutant promoter constructs. Following transfection, cells were treated with hypoxia (2\% oxygen) or pyruvate $(3 \mathrm{mM})$ for $12 \mathrm{~h}$ prior to measurement of luciferase activity. Each experiment was performed in quadruplicate and independently repeated two times. Error bars denote standard deviation (SD). The asterisk represents a statistically significant difference $(n=8, P<0.001)$.

respond to pyruvate or hypoxia. These data indicate that pyruvate, like hypoxia, is able to upregulate PAI-1 promoter activity via HRE-2.

HIF-1a binds to HRE-2 in the PAI-1 promoter under pyruvate treatment. Because the HRE-2 motif is required for pyruvateinduced PAI-1 transcription, we performed testing to determine whether HIF- $1 \alpha$ directly binds to the HRE- 2 motif using EMSA with a probe containing the HRE-2 sequence in the PAI-1 promoter. When the probed DNA fragment was incubated with the extract prepared from $3 \mathrm{mM}$ pyruvatetreated HepG2 cells, the shifted DNA probe and protein complex were observed (Fig. 4A). This complex was diminished by addition of 100 -fold molar excess competitor DNA. We then performed a supershift assay to show that the protein in the probe DNA-protein complex is indeed the HIF$1 \alpha$ protein. The probe DNA-protein complex was super- 


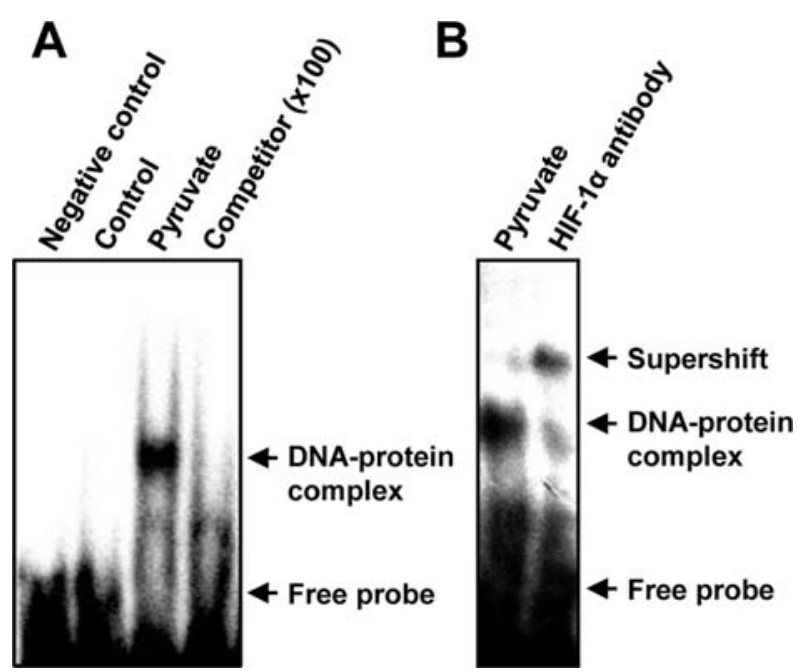

Figure 4. HIF-1 $\alpha$ binds to the HRE-2 motif in the PAI-1 promoter region by treatment with pyruvate. (A) Radiolabeled oligonucleotide was incubated with nuclear extracts from either pyruvate-treated cells or -untreated cells. For the competition assay, the radiolabeled probe was incubated with nuclear extract from pyruvate-treated cells with a cold probe in 100-fold molar excess. (B) For supershift analysis, the radiolabeled probe was incubated with nuclear extract from pyruvate treated cells. After initial binding, the anti-HIF- $1 \alpha$ antibody was added.

shifted by treatment with HIF-1 $\alpha$ antibody (Fig. 4B). These data indicate that pyruvate induces PAI-1 transcription by direct binding of HIF- $1 \alpha$ to the HRE-2 motif in the PAI-1 promoter.

\section{Discussion}

Most cancer cells that acquire malignant and glycolytic phenotypes obtain their supply of energy from aerobic glycolysis rather than oxidative phosphorylation. This phenomenon mostly results in accumulation of pyruvate, the glycolytic end-product (2,4-6). Findings from a recently reported study revealed that accumulated pyruvate acts as an inducer of tumor malignancy, not just as a metabolic intermediate. For example, Lu and his colleagues reported that pyruvate can stabilize HIF-1 $\alpha$ under normoxic conditions and can contribute to acceleration of glycolytic phenotypes of cancer cells through HIF-1 (4). We previously reported that pyruvate can activate endothelial cells through increased expression of angiogenic factors and promote their angiogenic activity (12). In this report, we examined the question of whether pyruvate can induce angiogenic activity of cancer cells. Tube formation of HUVECs was induced by CM derived from pyruvate-treated HepG2 (Fig. 1A). Because treatment with neutralizing antibody against PAI-1 inhibited tube formation, PAI-1 is responsible for tube formation (Fig. 1C). PAI-1, a member of the SERPIN (Serine Protease Inhibitor) family, is a major inhibitor of both tPA and uPA. The major physiological roles of PAI-1 are blood coagulation and tissue regeneration (17,31). In addition, PAI-1 also participates in various physiologic processes, including fibrinolysis, thrombosis, cancer metastasis, type-2 diabetes, tumor angiogenesis and senescence $(14,23,32-36)$. PAI-1 has been known to show dual-faced properties in angiogenesis.
Pharmacological concentration of PAI-1 has been reported to inhibit angiogenesis induced by FGF-2 (18). On the other hand, tumor angiogenesis was completely abolished in PAI1-deficient mice (20). Also, PAI-1 is pro-angiogenic at physiological (nanomolar) concentration (19). In our case, angiogenesis induced by $\mathrm{CM}$ derived from pyruvate-treated HepG2 might be explained by the action of secreted PAI-1 at the level of physiological concentration.

According to a recent report, PAI- 1 could be upregulated by HIF-1 under hypoxic conditions $(16,27)$. Therefore, we tested HIF-1-mediated PAI-1 expression by pyruvate. While pyruvate increased PAI-1 expression of both mRNA and protein, only the protein level of HIF-1 $\alpha$ was increased (Fig. 2). Increased expression of PAI- 1 by pyruvate is HIF- $1 \alpha$ dependent, as demonstrated by the fact that increased expression was diminished by treatment with YC-1, a pharmacological inhibitor of HIF-1. Moreover, HRE-2 of the five HREs in the PAI-1 promoter was essential for pyruvateinduced PAI-1 transcription (Fig. 3). Indeed, pyruvatestabilized HIF-1 bound to the HRE-2 (Fig. 4).

In consideration of several reports, as well as our results, HIF-1 can be activated under normoxia by several stimuli, including oncogenes, growth factors, cytokines, nitric oxide, oxidized low-density lipoprotein, lipopolysaccharide and pyruvate (4,37-39). Whereas the molecular mechanism for HIF-1 $\alpha$ stabilization by inhibition of prolyl hydroxylase domain (PHD) under hypoxia is well known, little is known about the stabilization of HIF- $1 \alpha$ under normoxia. Some recent reports have suggested that pyruvate can stabilize HIF-1 $\alpha$ under normoxia through PHD inhibition; however, the fine mechanism remains unknown (40). These reports provide evidence to support the suggestion that HIF-1 is a major factor in obtaining the properties for malignancy, aerobic glycolysis and angiogenesis. Taken together, our data indicate that accumulated pyruvate might play a role as an angiogenic inducer of cancer cells under normoxia and that pyruvateinduced angiogenesis through HIF-1 activation might be a therapeutic target for cancer treatment.

\section{Acknowledgements}

This work was supported for two years by Pusan National University Research Grant.

\section{References}

1. Kroemer G and Pouyssegur J: Tumor cell metabolism: cancer's Achilles' heel. Cancer Cell 13: 472-482, 2008.

2. Gatenby RA and Gillies RJ: Why do cancers have high aerobic glycolysis? Nat Rev Cancer 4: 891-899, 2004.

3. Kim JW, Gao P and Dang CV: Effects of hypoxia on tumor metabolism. Cancer Metastasis Rev 26: 291-298, 2007.

4. Lu H, Forbes RA and Verma A: Hypoxia-inducible factor 1 activation by aerobic glycolysis implicates the Warburg effect in carcinogenesis. J Biol Chem 277: 23111-23115, 2002.

5. Dang CV and Semenza GL: Oncogenic alterations of metabolism. Trends Biochem Sci 24: 68-72, 1999.

6. Galarraga J, Loreck DJ, Graham JF, et al: Glucose metabolism in human gliomas: correspondence of in situ and in vitro metabolic rates and altered energy metabolism. Metab Brain Dis 1: 279-291, 1986

7. Koch AE: Angiogenesis as a target in rheumatoid arthritis. Ann Rheum Dis 62 (Suppl. 2): S60-S67, 2003.

8. Folkman J: Angiogenesis and apoptosis. Semin Cancer Biol 13: 159-167, 2003. 
9. Bergers G and Benjamin LE: Tumorigenesis and the angiogenic switch. Nat Rev Cancer 3: 401-410, 2003.

10. Distler JH, Hirth A, Kurowska-Stolarska M, Gay RE, Gay S and Distler O: Angiogenic and angiostatic factors in the molecular control of angiogenesis. Q J Nucl Med 47: 149-161, 2003.

11. North S, Moenner M and Bikfalvi A: Recent developments in the regulation of the angiogenic switch by cellular stress factors in tumors. Cancer Lett 218: 1-14, 2005.

12. Lee MS, Moon EJ, Lee SW, Kim MS, Kim KW and Kim YJ: Angiogenic activity of pyruvic acid in in vivo and in vitro angiogenesis models. Cancer Res 61: 3290-3293, 2001.

13. Riccio A, Lund LR, Sartorio R, et al: The regulatory region of the human plasminogen activator inhibitor type-1 (PAI-1) gene. Nucleic Acids Res 16: 2805-2824, 1988

14. Liu Q, Moller U, Flugel D and Kietzmann T: Induction of plasminogen activator inhibitor I gene expression by intracellular calcium via hypoxia-inducible factor-1. Blood 104: 3993-4001, 2004.

15. Tacchini L, Matteucci E, De Ponti C and Desiderio MA: Hepatocyte growth factor signaling regulates transactivation of genes belonging to the plasminogen activation system via hypoxia inducible factor-1. Exp Cell Res 290: 391-401, 2003.

16. Fink T, Kazlauskas A, Poellinger L, Ebbesen P and Zachar V: Identification of a tightly regulated hypoxia-response element in the promoter of human plasminogen activator inhibitor-1. Blood 99: 2077-2083, 2002.

17. Agirbasli M: Pivotal role of plasminogen-activator inhibitor 1 in vascular disease. Int J Clin Pract 59: 102-106, 2005.

18. Ulisse S, Baldini E, Sorrenti S and D'Armiento M: The urokinase plasminogen activator system: a target for anti-cancer therapy. Curr Cancer Drug Targets 9: 32-71, 2009.

19. Devy L, Blacher S, Grignet-Debrus C, et al: The pro- or antiangiogenic effect of plasminogen activator inhibitor 1 is dose dependent. FASEB J 16: 147-154, 2002.

20. Bajou K, Masson V, Gerard RD, et al: The plasminogen activator inhibitor PAI-1 controls in vivo tumor vascularization by interaction with proteases, not vitronectin. Implications for antiangiogenic strategies. J Cell Biol 152: 777-784, 2001.

21. Waltz DA, Natkin LR, Fujita RM, Wei Y and Chapman HA: Plasmin and plasminogen activator inhibitor type 1 promote cellular motility by regulating the interaction between the urokinase receptor and vitronectin. J Clin Invest 100: 58-67, 1997.

22. Providence KM and Higgins PJ: PAI-1 expression is required for epithelial cell migration in two distinct phases of in vitro wound repair. J Cell Physiol 200: 297-308, 2004.

23. Binder BR, Mihaly J and Prager GW: uPAR-uPA-PAI-1 interactions and signaling: a vascular biologist's view. Thromb Haemost 97: 336-342, 2007.

24. Cullen JP, Nicholl SM, Sayeed S, et al: Plasminogen activator inhibitor-1 deficiency enhances flow-induced smooth muscle cell migration. Thromb Res 114: 57-65, 2004.

25. Soff GA, Sanderowitz J, Gately S, et al: Expression of plasminogen activator inhibitor type 1 by human prostate carcinoma cells inhibits primary tumor growth, tumor-associated angiogenesis, and metastasis to lung and liver in an athymic mouse model. J Clin Invest 96: 2593-2600, 1995.
26. Eitzman DT, Krauss JC, Shen T, Cui J and Ginsburg: Lack of plasminogen activator inhibitor-1 effect in a transgenic mouse model of metastatic melanoma. Blood 87: 4718-4722, 1996.

27. Kietzmann T, Roth U and Jungermann K: Induction of the plasminogen activator inhibitor-1 gene expression by mild hypoxia via a hypoxia response element binding the hypoxiainducible factor-1 in rat hepatocytes. Blood 94: 4177-4185, 1999.

28. Lau CK, Yang ZF, Lam CT, Tam KH, Poon RT and Fan ST: Suppression of hypoxia inducible factor-1alpha (HIF-1alpha) by YC-1 is dependent on murine double minute 2 (Mdm2). Biochem Biophys Res Commun 348: 1443-1448, 2006.

29. Yeo EJ, Chun YS, Cho YS, et al: YC-1: a potential anticancer drug targeting hypoxia-inducible factor 1. J Natl Cancer Inst 95: 516-525, 2003.

30. Shin DH, Kim JH, Jung YJ, et al: Preclinical evaluation of YC-1, a HIF inhibitor, for the prevention of tumor spreading. Cancer Lett 255: 107-116, 2007.

31. Lijnen HR: Pleiotropic functions of plasminogen activator inhibitor-1. J Thromb Haemost 3: 35-45, 2005.

32. Booth NA: Fibrinolysis and thrombosis. Baillieres Best Pract Res Clin Haematol 12: 423-433, 1999.

33. Yamamoto K, Takeshita K, Shimokawa T, et al: Plasminogen activator inhibitor-1 is a major stress-regulated gene: implications for stress-induced thrombosis in aged individuals. Proc Natl Acad Sci USA 99: 890-895, 2002.

34. Mazar AP, Henkin J and Goldfarb RH: The urokinase plasminogen activator system in cancer: implications for tumor angiogenesis and metastasis. Angiogenesis 3: 15-32, 1999.

35. He G, Bruun JM, Lihn AS, Pedersen SB and Richelsen B: Stimulation of PAI-1 and adipokines by glucose in human adipose tissue in vitro. Biochem Biophys Res Commun 310: 878-883, 2003.

36. Kortlever RM, Higgins PJ and Bernards R: Plasminogen activator inhibitor- 1 is a critical downstream target of p53 in the induction of replicative senescence. Nat Cell Biol 8: 877-884, 2006.

37. Knowles HJ, Mole DR, Ratcliffe PJ and Harris AL: Normoxic stabilization of hypoxia-inducible factor-1alpha by modulation of the labile iron pool in differentiating U937 macrophages: effect of natural resistance-associated macrophage protein 1 . Cancer Res 66: 2600-2607, 2006.

38. Wenger RH: Cellular adaptation to hypoxia: $\mathrm{O}_{2}$-sensing protein hydroxylases, hypoxia-inducible transcription factors, and $\mathrm{O}_{2}$ regulated gene expression. FASEB J 16: 1151-1162, 2002.

39. Zagorska A and Dulak J: HIF-1: the knowns and unknowns of hypoxia sensing. Acta Biochim Pol 51: 563-585, 2004.

40. Lu H, Dalgard CL, Mohyeldin A, McFate T, Tait AS and Verma A: Reversible inactivation of HIF-1 prolyl hydroxylases allows cell metabolism to control basal HIF-1. J Biol Chem 280: 41928-41939, 2005. 